\title{
Secondary prevention of cardiovascular diseases: current state of the art
}

\author{
Gerd Hasenfuß \\ Department of Cardiology and Pneumology, Heart Centre - University Medical Centre Göttingen, \\ German Centre for Cardiovascular Research, Göttingen, Germany
}

\begin{abstract}
A b stract
Prevention strategies for cardiac events depend of the risk for such an event. A very high risk is defined as a risk $>10 \%$ over 10 years. For example, a patient with known coronary artery disease has such a very high risk of death. However, a patient with diabetes and severe hypertension without known coronary artery disease carries the same risk. Here, secondary prevention and primary prevention overlap. Prevention guidelines include a number of general recommendations, such as changes in behaviour, nutrition, body weight, and physical activity as well as smoking intervention strategies. Drug treatment-based prevention strategies address diabetes mellitus, hypercholesterolaemia, platelet aggregation, and arterial hypertension. Following hospitalisation for heart failure or acute coronary syndrome, participation in a centre-based or home-based rehabilitation programme is recommended. There are a number of new treatment options with a promising potential to reduce the rate of events in patients with cardiovascular diseases and in patients with cardiovascular risk factors. Very recent treatment strategies include the PCSK9 inhibitors for hypercholesterolaemia and the SGLT2 inhibitors for reduction of cardiovascular events in patients with diabetes mellitus and increased cardiovascular risk.
\end{abstract}

Key words: prevention, cardiovascular disease, intervention, treatment

Kardiol Pol 2018; 76, 12: 1671-1679

\section{INTRODUCTION}

Secondary prevention of cardiovascular diseases (CVDs) is a major effort of a non-interventional cardiologist or internist. Secondary prevention of CVD means prevention of progression or recurrence of coronary artery disease (CAD) or CVD in general. It is worth highlighting that secondary prevention of CVD also means prevention of endocarditis, sudden cardiac death, rheumatic fever, stroke, and heart failure (HF) or HF decompensation. However, this review is focused on CAD.

\section{SCORE CHARTS}

The 2016 European Society of Cardiology (ESC) guidelines on CVD prevention in clinical practice [1] provided a risk score chart showing the 10-year risk of fatal CVD [1]. A very high risk is defined as $>10 \%$ risk of fatal CVD over 10 years, while a high risk is defined as $5 \%$ to $10 \%$ risk of death related to CVD. The chart presents data for women and men divided into smokers and non-smokers [1]. It also includes data on age, which is known to be the most prominent CVD risk factor, as well as blood pressure and cholesterol level.
For example, a 55-year-old male smoker who has a systolic blood pressure of $160 \mathrm{mmHg}$ and total cholesterol level of $5.0 \mathrm{mmol} / \mathrm{L}(200 \mathrm{mg} / \mathrm{dL}$ ) would be classified as having $11 \%$ risk of suffering from a fatal cardiovascular (CV) event over 10 years (a very high-risk patient).

Comparison of the total CV event risk, including stroke, myocardial infarction (MI), peripheral artery disease (PAD), or artery dissection, with the fatal CV risk shows that in general, the total CV event risk is three (in men) or four (in women) times higher than the fatal CV risk. What is interesting, the risk of a fatal CV event differs considerably across countries, and there are also significant differences within Europe [2]. For example, in Poland the CV mortality is higher (> 450/100,000 for male patients and $>350 / 100,000$ for female patients per year) as compared with Germany, which is a low-risk country (> 225/100,000 for men and > 175/100,000 for women per year).

There is a significant overlap between primary prevention and secondary prevention, which can be easily seen in the very high-risk category. A very high risk of a CV event,

\section{Address for correspondence:}

Dr. Gerd Hasenfuß, Herzzentrum, Klinik für Kardiologie und Pneumologie, Universitätsmedizin Göttingen, Georg-August-Universität Göttingen, Robert-Koch-Str. 40, 37075, Göttingen, Deutschland, e-mail: hasenfus@med.uni-goettingen.de
Received: 24.09 .2018
Accepted: 24.09 .2018
Available as AoP: 24.09.2018

Kardiologia Polska Copyright (C) Polish Cardiac Society 2018 
even a fatal CV event, is present in patients who have already experienced a documented CVD or CAD, in patients after $\mathrm{MI}$ or acute coronary syndrome (ACS), after stroke or transient ischaemic attack (TIA), with aortic aneurysm or PAD; so, all patients who have a documented atherosclerotic vascular disease are classified into a very high-risk group. However, patients with diabetes mellitus (DM), target organ damage such as proteinuria, or DM with an additional risk factor (tobacco smoking, marked hypercholesterolaemia, or markedly elevated blood pressure) are also included in the very high-risk group, even if they do not have documented CVD. The same is true for patients with severe chronic kidney disease, defined as estimated glomerular filtration rate (eGFR) $<30 \mathrm{~mL} / \mathrm{min} / 1.73 \mathrm{~m}^{2}$ or those with a calculated risk SCORE $\geq 10 \%$ [1]. A low-risk CVD category denotes $<1 \%$ risk of fatal CVD events within 10 years. Overall, there is a differentiation between primary and secondary prevention, but both overlap in the very high-risk group. The prevention strategies of CVD are the same for a patient with the presence of atherosclerotic vascular disease or a diabetic patient with marked hypertension, because both have a high risk (same strategies for secondary and primary prevention). This is important because it is highly relevant for the recommended strategies.

\section{GENERAL RECOMMENDATIONS}

In the literature there have been a number of general recommendations for primary and secondary prevention of CVD. For example, there is a recommendation for an annual influenza vaccination and the guidelines state that this may be considered in patients with established CVD (class Ilb, level of evidence C) [1-6]. This recommendation may be considered; its class and the level of evidence indicate that it is an expert opinion and there are no randomised controlled trials (RCTs) actually showing that this recommendation is associated with a morbidity or mortality benefit.

The guidelines include a number of general recommendations with respect to changes in behaviour, smoking intervention strategies, nutrition, correct body weight and body weight change, or physical activity [1]. There is a strong recommendation to use established cognitive-behavioural strategies (e.g. motivational interviewing) with involvement of multidisciplinary health care professionals (e.g. nurses, dieticians, psychologists), particularly in subjects at very high CVD risk, who require multimodal interventions including education on healthy lifestyle, physical activity, stress management, and psychosocial counselling, to support lifestyle changes (class I, level of evidence A) [7-10]. Regarding smoking of tobacco, all smokers should be identified and advised on quitting using the follow-up support, nicotine replacement therapies, as well as varenicline and bupropion in monotherapy or in combination (class I, level of evidence A) [11-14]. It is recommended that smoking of herbal products like tobacco, both actively and passively, be stopped (class I, level of evidence B) [15-21].

There is consensus that a healthy diet is strongly recommended in CVD prevention (class I, level of evidence B) [22]. This recommendation is related to another stating that overweight and obese individuals should achieve a normal weight or aim for a reduction in weight in order to improve the $\mathrm{CV}$ risk profile through a decrease in blood pressure, elevated cholesterol and triglycerides, and risk of developing type 2 DM (class I, level of evidence A) [23, 24].

There is no doubt that these recommendations are important and should be implemented.

\section{CHOLESTEROL-LOWERING AGENTS}

Regarding drug-treatment recommendations, the first important strategy is for lipid control treatment, which is recommended in patients at a very high CV risk, i.e. those with $\mathrm{CV}$ atherosclerotic disease, or a very high-risk factor, e.g. DM, cigarette smoking, or arterial hypertension. For these patients the low-density lipoprotein cholesterol (LDL-C) goal is $<1.8 \mathrm{mmol} / \mathrm{L}(<70 \mathrm{mg} / \mathrm{dL})$, or a reduction of at least $50 \%$ if the baseline level is between 1.8 and $3.5 \mathrm{mmol} / \mathrm{L}$ (70 and $135 \mathrm{mg} / \mathrm{dL}$ ) [1]. This is a class I recommendation; therefore, this goal should definitely be reached [25-28].

If a patient is in the high-risk category (but not the very high-risk category), the LDL-C level should unquestionably be $<2.5 \mathrm{mmol} / \mathrm{L}(<100 \mathrm{mg} / \mathrm{dL})$. For example, this target level of LDL-C refers to a patient without a proven CVD, who has a high blood pressure and suffers from DM as well as chronic kidney disease. Usually the first step to reach the target LDL-C level is to prescribe a statin, but if it is not possible, there are now two options. The first is to administer ezetimibe, and the other is to use one of the antibodies that inhibit proprotein convertase subtilisin-kexin type 9 (PCSK9), substantially reducing LDL-C levels by $60 \%$, as shown for the monoclonal antibody, evolocumab [29], which was evaluated in a large RCT published in 2017 in the New England Journal of Medicine [30]. In the FOURIER study involving 27,564 patients with atherosclerotic vascular disease and LDL-C $>70 \mathrm{mg} / \mathrm{dL}$ ( $>1.8 \mathrm{mmol} / \mathrm{L}$ ), evolocumab given subcutaneously every two weeks on a background of statin therapy was assessed in comparison with a statin plus placebo [30]. The mean reduction in LDL-C on evolocumab was 59\% compared with placebo. The primary endpoint was the composite of $\mathrm{CV}$ death, MI, stroke, hospitalisation for unstable angina, or coronary revascularisation. There was a significant reduction of the risk for the primary endpoint in patients receiving evolocumab vs. placebo $(9.8 \%$ vs. $11.3 \%, p<0.001)$ with no difference regarding adverse events, including neurocognitive events [30]. However, a disappointing result was no significant reduction in all-cause mortality, which stimulated a discussion on why this might have happened. 
The Cochrane Collaboration meta-analysis of 20 RCTs with a follow-up time of at least 24 weeks published up to March 2017 involved data on 67,237 participants aged 52 to 64 years (median 61 years), including trials testing different PCSK9 inhibitors (alirocumab, $\mathrm{n}=12$; bococizumab, $\mathrm{n}=3$, RG7652, $n=1$, and evolocumab, $n=4$ ) [31]. The authors confirmed a marked LDL-C reduction and demonstrated that "PCSK9 inhibitor use probably leads to little or no difference in mortality. Evidence on relative efficacy and safety when PCSK9 inhibitors were compared with active treatments was of low to very low quality; follow-up times were short, and events were few. Large trials with longer follow-up are needed to evaluate PCSK9 inhibitors versus active treatments as well as placebo. Owing to the predominant inclusion of high-risk patients in these studies, applicability of results to lower-risk groups is limited. Finally, estimated risk differences indicate that PCSK9 inhibitors only modestly change absolute risks (often to less than 1\%)" [31].

In March 2018 at the American College of Cardiology scientific sessions, the results of the Evaluation of Cardiovascular Outcomes After an Acute Coronary Syndrome During Treatment with Alirocumab (ODYSSEY OUTCOMES) study [32] were presented, in which a fully human monoclonal antibody to PCSK9, alirocumab, administered in biweekly injections, was used in 20,000 patients at one to 12 months after ACS, who were followed for four years. The investigators reported that there was a significant $(15 \%)$ reduction of all-cause death.

In the 2017 ESC guidelines for the management of acute $\mathrm{MI}$ in patients presenting with ST-segment elevation myocardial infarction (STEMI) [33] it is stated that additional lipid-lowering therapy is needed if the target LDL-C level of $<1.8 \mathrm{mmol} / \mathrm{L}(<70 \mathrm{mg} / \mathrm{dL})$ cannot be reached despite treatment with maximum-tolerated statin dose and ezetimibe (a cholesterol-absorption inhibitor that may reduce LDL levels by about $10 \%$ ) [34]. PCSK9 inhibitors are also a very important option for all patients who cannot tolerate statins.

\section{ANTIDIABETIC DRUGS}

Regarding recommendations for secondary prevention in DM patients, in the 2016 ESC prevention guidelines [1] it is said that the $\mathrm{HbA}_{1 \mathrm{c}}$ level which should be achieved in such patients is $<7 \%$ in general (class I, level of evidence $\mathrm{A}$ ). A target $\mathrm{HbA}_{1 \mathrm{c}}$ level of $<7 \%(<53 \mathrm{mmol} / \mathrm{mol})$ for the reduction in risk of CVD and microvascular complications in DM is recommended for most adults with either type 1 or type 2 DM, except for pregnant women (class I, level of evidence A) $[35,36]$. Among antidiabetic drugs, metformin is the first-line therapy following renal function evaluation [37].

However, it should be noted that geriatricians usually have a different view, and they generally recommend that in diabetic patients over 70 years old, the $\mathrm{HbA}_{1 \mathrm{c}}$ level should not be $<7 \%$, and in patients above 75 years old with a multimorbid disease it should be above $7.5 \%$. A major adverse event of key importance among elderly DM patients is hypoglycaemia [38]. Of note, diabetic patients including the elderly benefit particularly from statin therapy in terms of reduced CV risk [39, 40].

Another important recommendation, present already in 2016, is that in patients with type 2 DM and CVD the use of a sodium-glucose cotransporter 2 (SGLT2) inhibitor should be considered early in the course of the disease to reduce $\mathrm{CV}$ and overall mortality. The SGLT2 inhibitor is an inhibitor of a kidney transporter. It is important for the reabsorption of glucose from the urine into the blood, which causes glucosuria and lower blood glucose. It has been shown in a large number of patients and for a number of different drugs (starting with empagliflozin [41]) that the SGLT2 inhibitors reduce CV morbidity and mortality.

The EMPAgliflozin Removal of Excess Glucose: Cardiovascular OUTCOME Event Trial in Type 2 Diabetes Mellitus Patients (EMPA-REG OUTCOME) was the first CV outcome trial investigating a SGLT2 inhibitor, empagliflozin, in patients with type 2 DM. In this trial involving more than 7000 patients with DM and CVD the primary endpoints were CV death, MI, and stroke. Compared with placebo, the primary endpoints were significantly reduced in patients who were on empagliflozin in addition to previous antidiabetic medications. The indication for using empagliflozin was not primarily to reduce glucose. It has also been shown that empagliflozin reduced all-cause mortality [41]. Of note, it was also observed that these drugs reduce rates of hospitalisation for HF. The CANagliflozin CardioVascular Assessment Study (CANVAS) programme investigating another SGLT2 inhibitor, canagliflozin, in patients with type $2 \mathrm{DM}$ and high CV risk, was published in 2017 [42]. This study confirmed the findings of the empagliflozin study. The rate of the primary outcome, involving death from CV causes, nonfatal MI, or nonfatal stroke, was lower with canagliflozin than with placebo (hazard ratio [HR] 0.86; 95\% confidence interval [Cl] 0.75-0.97). There was also a benefit of canagliflozin regarding the progression of albuminuria (HR 0.73;95\% CI 0.67-0.79). Of note, canagliflozin was associated with an increased risk of amputation (HR 1.97; 95\% Cl 1.41-2.75), mainly at the level of the toe or the metatarsus [42].

The results of these trials were confirmed by $\mathrm{CV}$ data from the retrospective multinational study Comparative Effectiveness of Cardiovascular Outcomes in New Users of Sodium-Glucose Cotransporter-2 Inhibitors (CVD-REAL), in which SGLT2 inhibitors were compared with other classes of glucose-lowering drugs [42]. It has been reported that the use of SGLT2 inhibitors was associated with decreased risk of death and HF [43].

Currently in many institutions patients with DM and CVD, in particular those with $\mathrm{HF}$, are treated with empagliflozin or canagliflozin, regardless of whether there is an additional need to improve glucose levels. 


\section{ANTIPLATELET DRUGS}

Agents that inhibit platelet function remain the mainstay of secondary prevention of CVD. Lifelong use of low-dose acetylsalicylic acid (ASA) is recommended in all patients with proven atherosclerotic CVD [1]. However, low-dose ASA is not recommended in at-risk patients without proven atherosclerotic CVD (primary prevention). There have been a number of studies showing that if CV atherosclerotic disease is absent, use of ASA in such patients does not confer any benefit with respect to CV risk, but a higher risk of bleeding is observed. ASA should also be administered in patients after ischaemic stroke and after TIA, except for those with any type of atrial fibrillation (AF), who require lifelong oral anticoagulation.

In patients with ACS, ASA should be given to all individuals without contraindications at an initial loading dose of 150 to $300 \mathrm{mg}$, and a $\mathrm{P}_{2 Y_{12}}$ inhibitor should be added to ASA as soon as possible. Then ASA should be given at a dose of 75 to 100 mg daily, while the $\mathrm{P}_{2} \mathrm{Y}_{12}$ inhibitor should be maintained over 12 months, unless there are contraindications (class I, level of evidence A) [44-48].

A proton pump inhibitor (preferably not omeprazole) is strongly recommended in patients receiving dual antiplatelet therapy, who have a history of gastrointestinal bleeding or peptic ulcer, and it should be considered in the case of multiple other risk factors of bleeding, including Helicobacter pylori infection, age $\geq 65$ years, concurrent oral anticoagulation, or use of corticosteroids (class I, level of evidence A) [49-51]. Ticagrelor (180-mg loading dose, $90 \mathrm{mg}$ twice daily) is recommended for all patients at moderate-to-high risk of ischaemic events (e.g. elevated cardiac troponins), regardless of the initial treatment strategy (class I, level of evidence A) [48], whereas clopidogrel (300-mg loading dose, 75-mg daily dose) is the first-line therapy for patients with contraindications to ticagrelor or prasugrel (class I, level of evidence A) [46, 52, 53].

In the future the treatment of stable CVD may change after the Cardiovascular Outcomes for People Using Anticoagulation Strategies (COMPASS) trial [54], which was published in the New England Journal of Medicine in 2017. In this superiority study, a huge number of patients with stable CAD or PAD, i.e. 27,395 participants ( $22 \%$ women) at a mean age of 68 years from 602 centres in 33 countries, were randomised to a non-vitamin $\mathrm{K}$ antagonist oral anticoagulant (NOAC), the direct factor $\mathrm{Xa}$ inhibitor, rivaroxaban, at a very low dose (2.5 mg twice a day) plus ASA $100 \mathrm{mg} /$ day as compared to rivaroxaban $5 \mathrm{mg}$ twice a day or ASA alone. The primary endpoints in the COMPASS trial were CV death, stroke, and MI. The highest end point rate was found for ASA alone, while ASA plus rivaroxaban $2.5 \mathrm{mg}$ twice a day showed a significant reduction of primary endpoints (HR 0.76) as well as in mortality and ischaemic stroke (Fig. 1). Benefits in terms of CV events were observed despite the fact that $90 \%$ of study participants were treated with statins. An increased risk of major bleeding was shown in the rivaroxaban plus ASA group vs. the ASA group (incidence $3.1 \%$ vs. 1.9\%, HR 1.70; 95\% Cl 1.40-2.05), but this did not relate to fatal or nonfatal intracranial bleeding $(0.2 \%$ vs. $0.1 \%$ and $0.2 \%$ vs. $0.2 \%$, respectively). Limitations of this trial include exclusion of patients with recent stroke, severe HF, or end-stage renal disease, no determination of baseline low-density lipoprotein levels to assess statin therapy, and early termination of the trial (February 2017, a year ahead of time), which may have overestimated the treatment effect.

Recently, the COMPASS investigators have shown that, compared with ASA alone, rivaroxaban $2.5 \mathrm{mg}$ twice a day combined with ASA lowered the incidence of severe limb ischaemia leading to an intervention or major vascular amputation by $43 \%$, total vascular amputations by $58 \%$, peripheral vascular interventions by $24 \%$, and all peripheral vascular outcomes by $24 \%$ [55]. This convincingly indicates that the combination of rivaroxaban $2.5 \mathrm{mg}$ twice a day and ASA could be a valuable therapeutic option for patients with PAD. The COMPASS trial supports the concept of combined antithrombotic therapy as an important component of long-lasting effective CV prevention.

It is well established that antiplatelet therapy is needed after ACS [1], and in most patients a combination of low-dose ASA with a P2Y $Y_{12}$ an_ADP receptor inhibitor, for 12 months is used. There are potential deviations from this rule. In ACS patients with a high bleeding risk the duration of dual antiplatelet therapy (DAPT) may be reduced to between three and six months. However, after the results of the PEGASUS trial were published [56], in patients with a very high $C V$ risk and no particular bleeding risk a longer therapy (over three years), precisely a combination of ASA $100 \mathrm{mg} /$ day with ticagrelor $60 \mathrm{mg}$ twice a day, may be considered.

The ESC guidelines on DAPT in CAD were published in September 2017 [57]. After a percutaneous coronary intervention $(\mathrm{PCl})$ the strategies are different depending on whether it was a stable CAD or an ACS. In stable CAD the use of ASA and clopidogrel is recommended for at least six months, regardless of the type of stent that has been implanted, but in patients with high bleeding risk the duration of the combination therapy may be reduced to three months or to one month [57]. In patients with ACS the standard therapy is 12 months of DAPT. Patients with STEMI at high gastrointestinal bleeding risk should receive a proton pump inhibitor together with DAPT $[58,59]$. In most European centres ticagrelor or prasugrel are preferred over clopidogrel in combination with ASA. In STEMI patients with a high bleeding risk, DAPT should be recommended for at least six months, and then the $\mathrm{P}_{2} \mathrm{Y}_{12}$ inhibitor should be discontinued (class Ila, level of evidence B) $[60,61]$, but in such patients prasugrel should not be used; clopidogrel or ticagrelor are the preferred options. DAPT is also recommended in STEMI patients who did not undergo $\mathrm{PCl}$, and its duration should be 12 months, except for patients with excessive bleeding risk (class lla, level of evidence C) [33].

STEMI patients in whom left ventricular thrombus was detected should receive anticoagulation for up to six months. Therapy should be guided by repeated imaging $[62,63]$. 


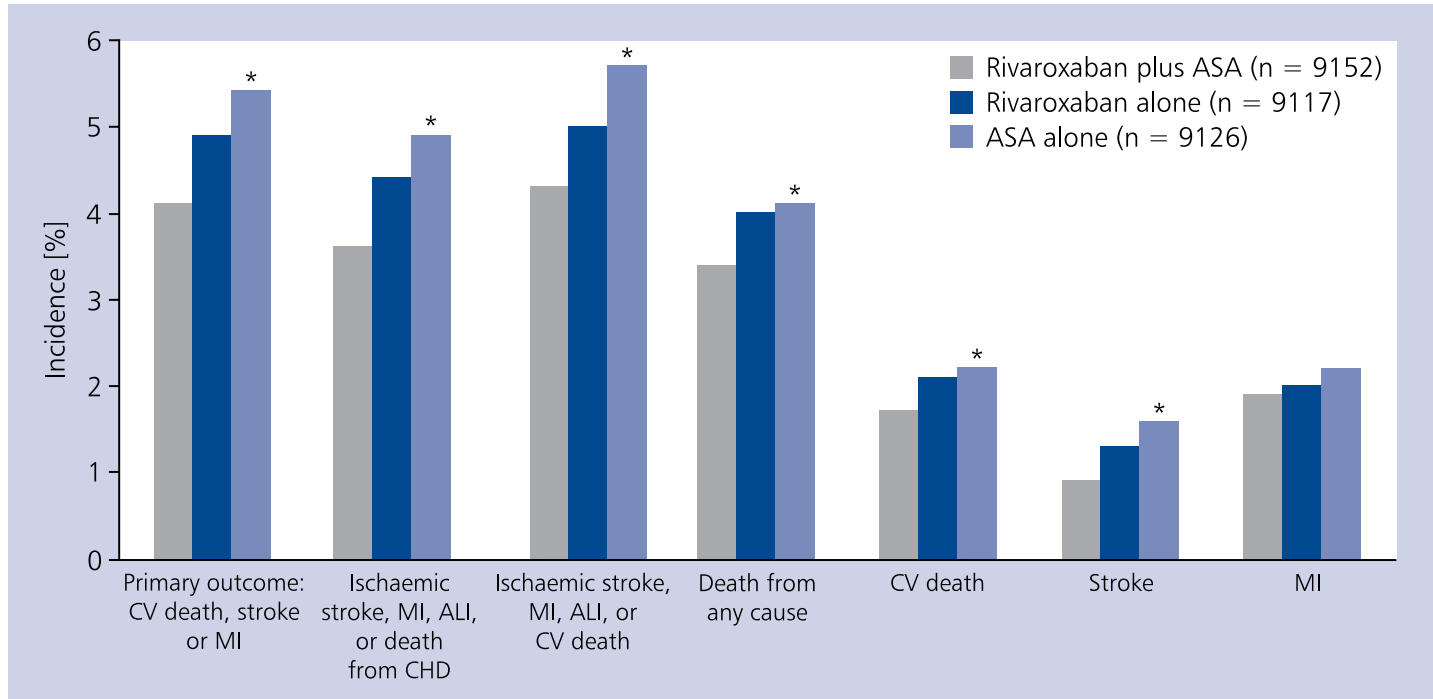

Figure 1. Clinical efficacy outcomes from the COMPASS trial (based on [66]). Patients on rivaroxaban 2.5 mg twice a day combined with acetylsalicylic acid (ASA) $100 \mathrm{mg} /$ day compared with those treated with ASA alone had lower risk of most cardiovascular events, including death; only the risk of myocardial infarction (MI) was similar in both groups; * $p<0.05$ for differences between the rivaroxaban-plus-ASA arm and the ASA-alone arm. No significant differences were observed between the rivaroxaban-alone and the ASA-alone arms except for the secondary outcome including ischaemic stroke, MI, acute limb ischaemia (ALI), or cardiovascular (CV) death; CHD - coronary heart disease

In a number of patients, particularly in those with $A F$, triple antithrombotic therapy, involving two antiplatelet drugs in combination with a vitamin $\mathrm{K}$ antagonist (VKA) or a NOAC, is needed following $\mathrm{PCI}[57,64]$. In patients who require chronic anticoagulation, the therapeutic options are now more complicated. Generally, in triple antithrombotic therapy prasugrel or ticagrelor should not be used. The use of ASA and clopidogrel with an anticoagulant is recommended. The absolute minimum of such a triple-therapy treatment after $\mathrm{PCl}$ is one month, and then two drugs should be continued, ASA or clopidogrel plus a NOAC or a VKA for an additional 11 months. In AF patients who experienced ACS the triple therapy should be given for up to six months, and then changed for the dual antithrombotic therapy (ASA/clopidogrel + NOAC/VKA) for an additional six months. Then the AF patients should receive a NOAC or a VKA alone [64].

In a patient with a very high bleeding risk, in order to avoid anticoagulation, one may decide to implant a left atrial appendage occluder in addition to using antiplatelet therapy [64].

\section{ANTIHYPERTENSIVE DRUGS}

In hypertensive patients who are at high CV risk, starting from grade 1 or 2 hypertension, drug treatment should be considered (class Ila, level of evidence B) [65]. Experts recommend initiating the therapy of arterial hypertension with a two-drug combination in patients with markedly elevated baseline blood pressure or high $\mathrm{CV}$ risk, suggesting also that such a combination in a single pill may be considered because of improved adherence (class IIb, level of evidence C) [66]. Regarding various classes of antihypertensive drugs, the following ESC recommendations were published in 2016 [1]:

- $\beta$-blockers in all patients with reduced left ventricular systolic function (left ventricular ejection fraction $[$ LVEF] $\leq 40 \%$ ) (level of evidence A);

- angiotensin converting enzyme inhibitors (ACEIs) within $24 \mathrm{~h}$ in all patients with LVEF $\leq 40 \%$ and in patients with HF, DM, hypertension, or chronic kidney disease, unless contraindicated (level of evidence A), to prevent recurrent ischaemic events (level of evidence B);

- angiotensin receptor blockers in patients who are intolerant to ACEI (level of evidence B);

- eplerenone, an aldosterone blocker, in patients with prior $\mathrm{MI}$ receiving $\mathrm{ACEl}$ and $\beta$-blockers, who have an $\mathrm{LVEF} \leq 35 \%$ and either DM or HF, with serum creatinine $<221 \mu \mathrm{mol} / \mathrm{L}$ $(<2.5 \mathrm{mg} / \mathrm{dL})$ for men and $<177 \mu \mathrm{mol} / \mathrm{L}(<2.0 \mathrm{mg} / \mathrm{dL})$ for women or normokalaemia (level of evidence A).

Pharmacological prophylaxis is supported also by national preventive initiatives [67].

\section{REHABILITATION PROGRAMMES}

There is a strong recommendation to encourage patients hospitalised for an ACS or revascularisation to participation in a cardiac rehabilitation programme. The same holds true for patients with HF [68, 69]. Of note, the 2017 updated Cochrane systematic review of 23 RCTs ( $n=2890)$, which 
compared centre-based cardiac rehabilitation (including hospitals) with home-based programmes in patients with $\mathrm{MI}$, angina, $\mathrm{HF}$, or a history of revascularisation, indicated that the two interventions provide similar effects in terms of improving clinical and health-related quality of life outcomes [70].

In current guidelines there is consensus that stable patients with CVD should take part in preventive programmes for therapy optimisation, adherence, and risk factor management [71-75]. Implementation of these recommendations in everyday practice is suboptimal worldwide.

\section{ANTI-INFLAMMATORY AGENTS}

Lately, a new strategy to treat the residual CVD risk related to inflammation has been successfully tested. This strategy has been shown in the recently published Canakinumab Anti-inflammatory Thrombosis Outcome Study (CANTOS) trial [76]. The study evaluated anti-inflammatory therapy with a fully human monoclonal interleukin- $1 \beta$ antibody, canakinumab, in 10,061 patients with atherosclerotic vascular disease, following previous $\mathrm{MI}$, who were either on statin or on conventional therapy of CVD with elevated highly-sensitive C-reactive protein $\geq 2.0 \mathrm{mg} / \mathrm{L}$. Patients at a mean age of 61 years were randomised to an interleukin- $1 \beta$ antibody, canakinumab, at a dose of $50 \mathrm{mg}, 150 \mathrm{mg}$, or $300 \mathrm{mg}$, administered subcutaneously every three months, or placebo. The primary endpoints in the CANTOS trial were non-fatal MI, non-fatal stroke, or CV death. As expected, use of all the three doses of canakinumab led to a significant decrease in C-reactive protein concentrations, by $26 \%, 37 \%$, and $41 \%$, respectively, with no impact on cholesterol levels. The results showed a significant reduction in the primary endpoints for 150-mg and 300-mg doses of canakinumab at a median follow-up of 3.7 years (HR 0.85 and HR 0.86, respectively). Importantly, an increase in the rate of fatal infections was observed among patients receiving canakinumab (incidence rate, 0.31 vs. 0.18 events [for placebo] per 100 person-years; $p=0.02$ ), despite the fact that patients with a history of chronic or recurrent infection, an immunocompromised state, a history or high risk of tuberculosis or disease related to the human immunodeficiency virus, or using other anti-inflammatory treatments, were excluded [76]. The authors concluded that "anti-inflammatory therapy targeting the interleukin- $1 \beta$ innate immunity pathway with canakinumab at a dose of $150 \mathrm{mg}$ every three months led to a significantly lower rate of recurrent cardiovascular events than placebo, independent of lipid-level lowering" [76].

\section{SUMMARY}

Secondary prevention of CVD equals primary prevention in patients with the highest risk. The important drugs in the prevention include antiplatelet drugs, statins, antihypertensive medications, and antidiabetic agents, including some new options, i.e. the SGLT2 inhibitors, the PCSK9 inhibitors, and potentially the combination of low-dose ASA and rivaroxaban
$2.5 \mathrm{mg}$ twice a day Now we may look to the future to learn more about the new anti-inflammatory therapies.

A review based on a lecture given at the $4^{\text {th }}$ McMaster International Review Course in Internal Medicine, Krakow, Poland, on $11^{\text {th }}$ May 2018.

Conflict of interest: Gerd Hasenfuß has received consulting fees and/or speaker honoraria from Servier, Novartis, AstraZeneca, Vifor Pharma, and Impulse Dynamics.

\section{References}

1. Piepoli M, Hoes A, Agewall S, et al. 2016 European Guidelines on cardiovascular disease prevention in clinical practice.The Sixth Joint Task Force of the European Society of Cardiology and Other Societies on Cardiovascular Disease Prevention in Clinical Practice. Eur Heart J. 2016; 37(29): 2315-2381, doi: 10.1093/eurheartj/ehw106.

2. Podolec P, Jankowski P, Zdrojewski T, et al. Polish Forum for Prevention Guidelines on Cardiovascular Risk Assessment: update 2016. Kardiol Pol. 2017; 75(1): 84-86, doi: 10.5603/KP.2017.0009, indexed in Pubmed: 28124785.

3. Smeeth L, Thomas S, Hall A, et al. Risk of myocardial infarction and stroke after acute infection or vaccination. N Engl J Med. 2004; 351(25): 2611-2618, doi: 10.1056/nejmoa041747.

4. Siriwardena AN, Gwini SM, Coupland CAC. Influenza vaccination, pneumococcal vaccination and risk of acute myocardial infarction: matched case-control study. CMAJ. 2010; 182(15): 1617-1623, doi: 10.1503/cmaj.091891, indexed in Pubmed: 20855479.

5. Gwini SM, Coupland CAC, Siriwardena AN. The effect of influenza vaccination on risk of acute myocardial infarction: self-controlled case-series study. Vaccine. 2011; 29(6): 1145-1149, doi: 10.1016/j.vaccine.2010.12.017, indexed in Pubmed: 21172383.

6. Udell JA, Zawi R, Bhatt DL, et al. Association between influenza vaccination and cardiovascular outcomes in high-risk patients: a meta-analysis. JAMA. 2013; 310(16): 1711-1720, doi: 10.1001/jama.2013.279206, indexed in Pubmed: 24150467.

7. Rubak S, Sandbaek A, Lauritzen T, et al. Motivational interviewing: a systematic review and meta-analysis. Br J Gen Pract. 2005; 55(513): 305-312, indexed in Pubmed: 15826439.

8. Artinian NT, Fletcher GF, Mozaffarian D, et al. Interventions to promote physical activity and dietary lifestyle changes for cardiovascular risk factor reduction in adults: a scientific statement from the American Heart Association. Circulation. 2010; 122(4): 406-441, doi:10.1161/CIR.0b013e3181e8edf1, indexed in Pubmed: 20625115.

9. Balady GJ, Williams MA, Ades PA, et al. American Heart Association Exercise, Cardiac Rehabilitation, and Prevention Committee, the Council on Clinical Cardiology, American Heart Association Council on Cardiovascular Nursing, American Heart Association Council on Epidemiology and Prevention, American Heart Association Council on Nutrition, Physical Activity, and Metabolism, American Association of Cardiovascular and Pulmonary Rehabilitation. Core components of cardiac rehabilitation/secondary prevention programs: 2007 update: a scientific statement from the American Heart Association Exercise, Cardiac Rehabilitation, and Prevention Committee, the Council on Clinical Cardiology; the Councils on Cardiovascular Nursing, Epidemiology and Prevention, and Nutrition, Physical Activity, and Metabolism; and the American Association of Cardiovascular and Pulmonary Rehabilitation. Circulation. 2007; 115(20): 2675-2682, doi: 10.1161/CIRCULATIONAHA.106.180945, indexed in Pubmed: 17513578. 
10. Piepoli MF, Corrà U, Benzer W, et al. Secondary prevention through cardiac rehabilitation: from knowledge to implementation. A position paper from the Cardiac Rehabilitation Section of the European Association of Cardiovascular Prevention and Rehabilitation. Eur J Cardiovasc Prev Rehabil. 2010; 17(1): 1-17, doi: 10.1097/HJR.0b013e3283313592, indexed in Pubmed: 19952757.

11. Cahill K, Stevens S, Perera R, et al. Pharmacological interventions for smoking cessation: an overview and network meta-analysis. Cochrane Database Syst Rev. 2013(5): CD009329, doi: 10.1002/14651858.CD009329.pub2, indexed in Pubmed: 23728690.

12. Hughes JR, Stead LF, Lancaster T. Antidepressants for smoking cessation. Cochrane Database Syst Rev. 2007; 1(CD000031).

13. Cahill K, Stead LF, Lancaster T, et al. Nicotine receptor partial agonists for smoking cessation. Cochrane Database Syst Rev. 2012(4): CD006103, doi:10.1002/14651858.CD006103.pub2, indexed in Pubmed: 17253581.

14. Hughes J, Stead L, Hartmann-Boyce J, et al. Antidepressants for smoking cessation. Cochrane Database Syst Rev. 2014; 1(CD00003), doi:10.1002/14651858.cd000031.pub4.

15. Doll R, Peto R, Boreham J, et al. Mortality in relation to smoking: 50 years' observations on male British doctors. BMJ. 2004 328(7455): 1519, doi:10.1136/bmj.38142.554479.AE, indexed in Pubmed: 15213107.

16. Kiiskinen U, Vartiainen E, Puska P, et al. Long-term cost and life-expectancy consequences of hypertension. J Hypertens. 1998; 16(8): 1103-1112, indexed in Pubmed: 9794712.

17. Prescott E, Hippe M, Schnohr P, et al. Smoking and risk of myocardial infarction in women and men: longitudinal population study. BMJ. 1998; 316(7137): 1043-1047, indexed in Pubmed: 9552903

18. Taylor T, Lader D, Bryant A, et al. Smoking-Related behaviour and attitudes, 2005. London: Office for National Statistics. 2006, doi:10.1037/e665212007-001.

19. West R. Key performance indicators: findings from the Smoking Toolkit Study. http:// www.smokinginengland.info.

20. He J, Vupputuri S, Allen K, et al. Passive smoking and the risk of coronary heart disease--a meta-analysis of epidemiologic studies. N Engl J Med. 1999; 340(12): 920-926, doi: 10.1056/NEJM199903253401204, indexed in Pubmed: 10089185

21. Law MR, Morris JK, Wald NJ. Environmental tobacco smoke exposure and ischaemic heart disease: an evaluation of the evidence. BMJ. 1997; 315(7114): 973-980, indexed in Pubmed: 9365294.

22. European Heart Network. Diet, Physical Activity and Cardiovascular Disease Prevention in Europe. Brussels, Belguim: European Heart Network. 2011.

23. Oreopoulos A, Padwal R, Norris CM, et al. Effect of obesity on short- and long-term mortality postcoronary revascularization: a meta-analysis. Obesity (Silver Spring). 2008; 16(2): 442-450, doi: 10.1038/oby.2007.36, indexed in Pubmed: 18239657.

24. Berrington de Gonzalez A, Hartge P, Cerhan JR, et al. Body-mass index and mortality among 1.46 million white adults. N Engl J Med. 2010; 363(23): 2211-2219, doi: 10.1056/NEJMoa1000367, indexed in Pubmed: 21121834.

25. Mihaylova B, Emberson J, Blackwell L, et al. The effects of lowering LDL cholesterol with statin therapy in people at low risk of vascular disease: meta-analysis of individual data from 27 randomised trials. Lancet. 2012; 380(9841): 581-590, doi: 10.1016/S0140-6736(12)60367-5, indexed in Pubmed: 22607822.

26. Robinson JG, Wang S, Smith BJ, et al. Meta-analysis of the relationship between non-high-density lipoprotein cholesterol reduction and coronary heart disease risk. J Am Coll Cardiol. 2009; 53(4): 316-322, doi: 10.1016/j.jacc.2008.10.024, indexed in Pubmed: 19161879
27. Nordestgaard BG, Chapman MJ, Humphries SE, et al. Familial hypercholesterolaemia is underdiagnosed and undertreated in the general population: guidance for clinicians to prevent coronary heart disease: consensus statement of the European Atherosclerosis Society. Eur Heart J. 2013; 34(45): 3478-3490, doi: 10.1093/eurhearti/eht273, indexed in Pubmed: 23956253.

28. Cannon CP, Blazing MA, Giugliano RP, et al. Ezetimibe added to statin therapy after acute coronary syndromes. N Engl J Med. 2015; 372(25): 2387-2397, doi: 10.1056/NEJMoa1410489, indexed in Pubmed: 26039521

29. Sabatine MS, Giugliano RP, Wiviott SD, et al. Open-Label Study of Long-Term Evaluation against LDL Cholesterol (OSLER) Investigators. Efficacy and safety of evolocumab in reducing lipids and cardiovascular events. N Engl J Med. 2015; 372(16): 1500-1509, doi: 10.1056/NEJMoa1500858, indexed in Pubmed: 25773607.

30. Sabatine MS, Giugliano RP, Keech AC, et al. Evolocumab and clinical outcomes in patients with cardiovascular disease. NEngl J Med. 2017; 376(18): 1713-1722, doi: 10.1056/NEJMoa1615664, indexed in Pubmed: 28304224.

31. Schmidt AF, Pearce LS, Wilkins JT, et al. PCSK9 monoclonal antibodies for the primary and secondary prevention of cardiovascular disease. Cochrane Database Syst Rev. 2017; 4(13): CD011748-1055, doi: 10.1002/14651858.CD011748.pub2, indexed in Pubmed: 28453187.

32. Schwartz GG, Steg PG, Szarek M, et al. ODYSSEY OUTCOMES Committees and Investigators. Alirocumab and cardiovascular outcomes after acute coronary syndrome. N Engl J Med. 2018; 379(22): 2097-2107, doi: 10.1056/NEJMoa1801174, indexed in Pubmed: 30403574 .

33. Ibanez B, James S, Agewall S, et al. 2017 ESC Guidelines for the management of acute myocardial infarction in patients presenting with ST-segment elevation: The Task Force for the management of acute myocardial infarction in patients presenting with ST-segment elevation of the European Society of Cardiology (ESC). Eur Heart J. 2018; 39(2): 119-177, doi: 10.1093/eurheartj/ehx393, indexed in Pubmed: 28886621.

34. Savarese G, De Ferrari GM, Rosano GMC, et al. Safety and efficacy of ezetimibe: A meta-analysis. Int J Cardiol. 2015; 201: 247-252, doi:10.1016/j.ijcard.2015.08.103, indexed in Pubmed: 26301648.

35. Holman RR, Paul SK, Bethel MA, et al. Intensive blood-glucose control with sulphonylureas or insulin compared with conventional treatment and risk of complications in patients with type 2 diabetes (UKPDS 33). UK Prospective Diabetes Study (UKPDS) Group. Lancet. 1998; 352(9131): 837-853, doi:10.1016/s01406736(98)07019-6, indexed in Pubmed: 9742976.

36. Patel A, MacMahon S, Chalmers J, et al. ADVANCE Collaborative Group. Intensive blood glucose control and vascular outcomes in patients with type 2 diabetes. N Engl J Med. 2008; 358(24): 2560-2572, doi: 10.1056/NEJMoa0802987, indexed in Pubmed: 18539916.

37. UK Prospective Diabetes Study (UKPDS) Group. Effect of intensive blood-glucose control with metformin on complications in overweight patients with type 2 diabetes (UKPDS 34). Lancet. 1998; 352(9131): 854-865, indexed in Pubmed: 9742977.

38. Gumprecht J, Nabrdalik K. Hypoglycemia in patients with insulintreated diabetes. Pol Arch Med Wewn. 2016; 126(11): 870-878, doi: 10.20452/pamw.3586, indexed in Pubmed: 27906880.

39. Colhoun HM, Betteridge DJ, Durrington PN, et al. Primary prevention of cardiovascular disease with atorvastatin in type 2 diabetes in the Collaborative Atorvastatin Diabetes Study (CARDS): multicentre randomised placebo-controlled trial. Lancet. 2004; 364(9435): 685-696, doi: 10.1016/S0140-6736(04)16895-5, indexed in Pubmed: 15325833.

40. Collins R, Armitage J, Parish S, et al. MRC/BHF Heart Protection Study of cholesterol-lowering with simvastatin in 5963 people with diabetes: a randomised placebo-controlled trial. Lancet. 2003; 361(9374): 2005-2016, indexed in Pubmed: 12814710. 
41. Zinman B, Wanner C, Lachin J, et al. Empagliflozin, Cardiovascular Outcomes, and Mortality in Type 2 Diabetes. N Engl J Med. 2015; 373(22): 2117-2128, doi: 10.1056/nejmoa1504720.

42. Neal B, Perkovic V, Mahaffey KW, et al. CANVAS Program Collaborative Group. Canagliflozin and cardiovascular and renal events in type 2 diabetes. N Engl J Med. 2017; 377(7): 644-657, doi: 10.1056/NEJMoa1611925, indexed in Pubmed: 28605608.

43. Cavender MA, Norhammar A, Birkeland KI, et al. SGLT-2 Inhibitors and Cardiovascular Risk: An Analysis of CVD-REAL. J Am Coll Cardiol. 2018; 71(22): 2497-2506, doi: 10.1016/j. jacc.2018.01.085, indexed in Pubmed: 29852973.

44. Baigent C, Blackwell L, Collins R, et al. Aspirin in the primary and secondary prevention of vascular disease: collaborative meta-analysis of individual participant data from randomised trials. Lancet. 2009; 373(9678): 1849-1860, doi: 10.1016/S01406736(09)60503-1, indexed in Pubmed: 19482214

45. Mehta SR, Tanguay JF, Eikelboom JW, et al. Double-dose versus standard-dose clopidogrel and high-dose versus low-dose aspirin in individuals undergoing percutaneous coronary intervention for acute coronary syndromes (CURRENT-OASIS 7): a randomised factorial trial. Lancet. 2010; 376(9748): 1233-1243, doi: 10.1016/S0140-6736(10)61088-4, indexed in Pubmed: 20817281.

46. Yusuf S, Zhao F, Mehta SR, et al. Effects of clopidogrel in addition to aspirin in patients with acute coronary syndromes without st-segment elevation. N Engl J Med. 2001; 345(7): 494-502, doi: 10.1056/nejmoa010746.

47. Wiviott S, Braunwald E, McCabe C, et al. Prasugrel versus clopidogrel in patients with acute coronary syndromes. N Engl J Med. 2007; 357(20): 2001-2015, doi: 10.1056/nejmoa0706482.

48. Wallentin L, Becker R, Budaj A, et al. Ticagrelor versus clopidogrel in patients with acute coronary syndromes. N Engl J Med. 2009; 361(11): 1045-1057, doi: 10.1056/nejmoa0904327.

49. O’Donoghue ML, Braunwald E, Antman EM, et al. Pharmacodynamic effect and clinical efficacy of clopidogrel and prasugrel with or without a proton-pump inhibitor: an analysis of two randomised trials. Lancet. 2009; 374(9694): 989-997, doi: 10.1016/S0140-6736(09)61525-7, indexed in Pubmed:19726078.

50. Abraham NS, Hlatky MA, Antman EM, et al. ACCF/ACG/AHA, ACCF/ACG/AHA. ACCF/ACG/AHA 2010 Expert Consensus Document on the concomitant use of proton pump inhibitors and thienopyridines: a focused update of the ACCF/ACG/AHA 2008 expert consensus document on reducing the gastrointestinal risks of antiplatelet therapy and NSAID use: a report of the American College of Cardiology Foundation Task Force on Expert Consensus Documents. Circulation. 2010; 122(24): 2619-2633, doi: 10.1161/CIR.0b013e318202f701, indexed in Pubmed: 21060077.

51. Bhatt D, Cryer B, Contant C, et al. Clopidogrel with or without omeprazole in coronary artery disease. N Engl J Med. 2010; 363(20): 1909-1917, doi:10.1056/nejmoa1007964

52. Mehta SR, Yusuf S, Peters RJ, et al. Effects of pretreatment with clopidogrel and aspirin followed by long-term therapy in patients undergoing percutaneous coronary intervention: the PCI-CURE study. Lancet. 2001; 358(9281): 527-533, indexed in Pubmed: 11520521.

53. Steinhubl SR, Berger PB, Mann JT, et al. Early and sustained dual oral antiplatelet therapy following percutaneous coronary intervention: a randomized controlled trial. JAMA. 2002; 288(19): 2411-2420, indexed in Pubmed: 12435254

54. Eikelboom J, Connolly S, Bosch J, et al. Rivaroxaban with or without aspirin in stable cardiovascular disease. N Engl J Med. 2017; 377(14): 1319-1330, doi: 10.1056/nejmoa1709118.

55. Anand SS, Caron F, Eikelboom JW, et al. Major adverse limb events and mortality in patients with peripheral artery disease: the compass trial. J Am Coll Cardiol. 2018; 71(20): 2306-2315, doi: 10.1016/j.jacc.2018.03.008, indexed in Pubmed: 29540326.

56. Bonaca $\mathrm{M}$, Bhatt $\mathrm{D}$, Cohen $\mathrm{M}$, et al. Long-Term use of ticagrelor in patients with prior myocardial infarction. N Engl J Med. 2015; 372(19): 1791-1800, doi: 10.1056/nejmoa1500857.

57. Valgimigli M, Bueno H, Byrne RA, et al. [2017 ESC focused update on dual antiplatelet therapy in coronary artery disease developed in collaboration with EACTS]. Kardiol Pol. 2017; 75(12): 1217-1299.

58. Bhatt D, Cryer B, Contant C, et al. Clopidogrel with or without omeprazole in coronary artery disease. N Engl J Med. 2010; 363(20): 1909-1917, doi:10.1056/nejmoa1007964.

59. Costa F, Tijssen JG, Ariotti S, et al. Incremental Value of the CRUSADE, ACUITY, and HAS-BLED Risk Scores for the Prediction of Hemorrhagic Events After Coronary Stent Implantation in Patients Undergoing Long or Short Duration of Dual Antiplatelet Therapy. J Am Heart Assoc. 2015; 4(12), doi:10.1161/JAHA.115.002524, indexed in Pubmed: 26643501.

60. Palmerini T, Della Riva D, Benedetto U, et al. Three, six, or twelve months of dual antiplatelet therapy after DES implantation in patients with or without acute coronary syndromes: an individual patient data pairwise and network meta-analysis of six randomized trials and 11473 patients. Eur Heart J. 2017; 38(14): 1034-1043, doi: 10.1093/eurheartj/ehw627, indexed in Pubmed: 28110296.

61. Reeder GS, Lengyel M, Tajik AJ, et al. Mural thrombus in left ventricular aneurysm: incidence, role of angiography, and relation between anticoagulation and embolization. Mayo Clin Proc. 1981; 56(2): 77-81, indexed in Pubmed: 7464234.

62. Keeley EC, Hillis LD. Left ventricular mural thrombus after acute myocardial infarction. Clin Cardiol. 1996; 19(2): 83-86, indexed in Pubmed: 8821415.

63. Kirchhof P, Benussi S, Kotecha D, et al. [2016 ESC Guidelines for the management of atrial fibrillation developed in collaboration with EACTS]. Kardiol Pol. 2016; 74(12): 1359-1469.

64. Valgimigli M, Bueno H, Byrne RA, et al. 2017 ESC focused update on dual antiplatelet therapy in coronary artery disease developed in collaboration with EACTS: The Task Force for dual antiplatelet therapy in coronary artery disease of the European Society of Cardiology (ESC) and of the European Association for Cardio-Thoracic Surgery (EACTS). Eur Heart J. 2018; 39(3): 213-260, doi: 10.1093/eurheartj/ehx419, indexed in Pubmed: 28886622.

65. Mancia G, Fagard R, Narkiewicz K, et al. 2013 ESH/ESC Practice Guidelines for the Management of Arterial Hypertension. Blood Pressure. 2013; 23(1): 3-16, doi: 10.3109/08037051.201 4.868629 .

66. Gupta AK, Arshad S, Poulter NR. Compliance, safety, and effectiveness of fixed-dose combinations of antihypertensive agents: a meta-analysis. Hypertension. 2010; 55(2): 399-407, doi: 10.1161/HYPERTENSIONAHA.109.139816, indexed in Pubmed: 20026768.

67. Podolec P, Filipiak KJ, Undas A, et al. Polish forum for prevention guidelines on prophylactic pharmacotherapy: update 2017. Kardiol Pol. 2017; 75(5): 508-511, doi: 10.5603/KP.2017.0087, indexed in Pubmed: 28530029.

68. Anderson L, Taylor R. Cardiac rehabilitation for people with heart disease: an overview of Cochrane systematic reviews. Cochrane Database Syst Rev. 2014, doi: 10.1002/14651858.cd011273.pub2.

69. Anderson L, Oldridge N, Thompson DR, et al. Exercise-based cardiac rehabilitation for coronary heart disease. J Am Coll Cardiol. 2016; 67(2): 1-12.

70. Anderson L, Sharp GA, Norton RJ, et al. Home-based versus centre-based cardiac rehabilitation. Cochrane Database Syst Rev. 2017; 6: CD007130, doi: 10.1002/14651858.CD007130.pub4, indexed in Pubmed: 28665511. 
71. Clark RA, Conway A, Poulsen V, et al. Alternative models of cardiac rehabilitation: a systematic review. Eur J Prev Cardiol. 2015; 22(1): 35-74, doi:10.1177/2047487313501093, indexed in Pubmed: 23943649.

72. Karmali KN, Davies P, Taylor F, et al. Promoting patient uptake and adherence in cardiac rehabilitation. Cochrane Database Syst Rev. 2014(6):CD007131, doi: 10.1002/14651858.CD007131.pub3, indexed in Pubmed: 24963623.

73. McAlister FA, Lawson FM, Teo KK, et al. Randomised trials of secondary prevention programmes in coronary heart disease: systematic review. BMJ. 2001; 323(7319): 957-962, indexed in Pubmed: 11679383.
74. Murchie P, Campbell NC, Ritchie LD, et al. Secondary prevention clinics for coronary heart disease: four year follow up of a randomised controlled trial in primary care. BMJ. 2003; 326(7380): 84-528, indexed in Pubmed: 12521974.

75. Long L, Anderson L, Dewhirst AM, et al. Exercise-based cardiac rehabilitation for adults with stable angina. Cochrane Database Syst Rev. 2018; 2: CD012786, doi: 10.1002/14651858.CD012786. pub2, indexed in Pubmed: 29394453.

76. Ridker PM, Everett BM, Thuren T, et al. Antiinflammatory therapy with canakinumab for atherosclerotic disease. $\mathrm{N}$ Engl J Med. 2017; 377(12): 1119-1131, doi: 10.1056/NEJMoa1707914, indexed in Pubmed: 28845751.

Cite this article as: Hasenfuß G. Secondary prevention of cardiovascular diseases: current state of the art. Kardiol Pol. 2018; 76(12): 1671-1679, doi: 10.5603/KP.a2018.0198. 